American Journal of Animal and Veterinary Sciences 5 (2): 107-110, 2010

ISSN $1557-4555$

(C) 2010 Science Publications

\title{
Permanent Urethrostomy for Treatment of Caprine Hypospadias
}

\author{
${ }^{1}$ Omid Azari, ${ }^{1}$ Ehsanollah Sakhaee and ${ }^{2}$ Ladan Emadi \\ ${ }^{1}$ Department of Clinical Sciences, \\ ${ }^{2}$ Department of Basic Sciences, \\ Faculty of Veterinary Medicine, Shahid Bahonar University of Kerman, Kerman, Iran
}

\begin{abstract}
Hypospadias, a more extreme form of congenital urethral defect, is seen in young phenotypically male goats. In hypospadias, the urethra remains open on the ventral surface of the penis and is visible externally on the preputial midline. Problem statement: The purpose of this study was to evaluate the surgical treatment outcome in hypopadiac kids. Approach: Thirty six male goat kids with sings of hypospadias were referred to the Animal Hospital of Veterinary Medicine Faculty of Kerman, Iran. The age of patients ranged from one week to 3 months old. The kids were showed symptoms of dysuria and stranguria, during urination. Urine leaked into the subcutaneous tissue of ventral abdominal wall and prepuce. Surgical reconstruction is the only possible therapeutic option for hypospadias. In the current study, permanent urethrostomy operation was carried out for treatment of all kids. Results: Two weeks after surgery the goat kids were in good condition. After 2 months, no significant postoperative complications were observed. Conclusion: Permanent urethrostomy is a reliable technique to treatment of hypospadiac kids.
\end{abstract}

Key words: Hypospadias, goat, surgical treatment, urethrostomy

\section{INTRODUCTION}

Hypospadias is a rare congenital malformation of the urethra which has been reported in dogs, sheep, goats, cattle, rats, nonhuman primates and human (Alam et al., 2005). Hypospadias is imperfect closure of the external male urethra (Radostits et al., 2007). This congenital defect results from failure of fusion of the urogenital folds and incomplete formation of the penile urethra (Boothe, 2003). Hypospadias is accompanied by hypoplasia of the corpus cavernosum urethra (Fossum, 2002). Urine may pool within the prepuce and subcutaneous space, causing irritation and infection of penis and preputial lining (balanopostitis). The external urethral orifice can occur anywhere of the ventral aspect of the penis from the normal opening to the perineal regions, glandular, penile, scrotal and perineal hypospadis have been reported (Alam et al., 2005; Boothe, 2003; Fossum, 2002).

The etiology of hypospadias is not wellunderstood, it seems to be multifactorial, may be related to genetic, endocrinologicaland environmental factors (Silver, 2000). Surgical correction should be considered for treatment of hypospadias (Boothe, 2003). This study, presents surgical management in 36 hypospadiac goat kids.

\section{MATERIALS AND METHODS}

Over a 14 month period, from April 2007-June 2008, 36 goat kids with sings of hypospadias Fig. 1, were referred to the Animal Hospital of Veterinary Medicine Faculty, Shahid Bahonar University of Kerman, Iran. The age of patients ranged from one week to three months old. The owners declared that the kids have shown symptoms of dysuria and stranguria, during urination. In physical examination, the most of kids were depressed and Temperature, Pulse and Respiratory Rate (TPR) of all patients were in normal range. All of the kids were male, not hermaphrodites or pseudohermaphrodites. The kids were restrained in dorsal recumbency; the preputial skin was retracted caudally and it was observed that the urethral process and glans was lightly adhered to the prepuce in some of cases. The preputial orifice was small and narrow. The most obvious clinical finding was urethral diverticulum in different size, which located in ventral part of penis, caudal to the preputial orifice. Manual pressure on the diverticulum caused dribbling of urine from the urethral orifice. In some cases congenital defect such as ectopic penis, located between anus and scrotum (one case) was seen. In one goat opening of urethra was located in the scrotal region and in the others were in penile position.

Corresponding Author: Omid Azari, Department of Clinical Sciences, Faculty of Veterinary Medicine,

Shahid Bahonar University of Kerman, Kerman, Iran 


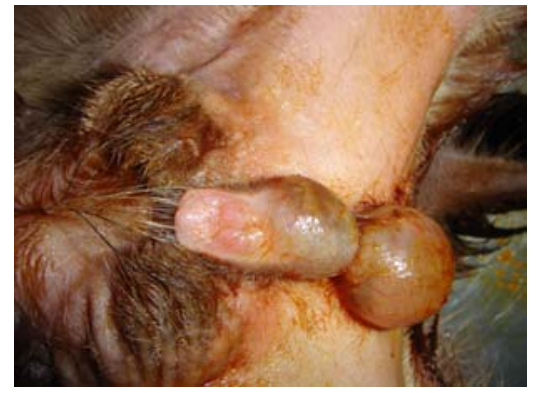

Fig. 1: Hypospadias in goat kids, Urine leaked into the subcutaneous tissue of ventral abdominal wall, ectopic penis

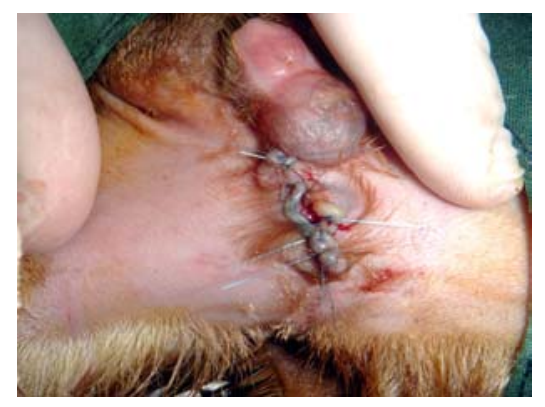

Fig. 2: Permanent urethrostomy in hypospadiac goat

Ultrasonography examination was carried out in some cases and showed that the diverticulum and bladder were fluid-filled, without any abnormality in abdominal cavity.

Blood and urine samples were taken from 14 of 36 cases in different flocks and submitted to Laboratory of Teaching and Research Hospital of Veterinary Medicine Faculty of Kerman, Iran. Results revealed that hematologic (PCV, RBC, $\mathrm{Hb}, \mathrm{WBC}$ and neutrophil/lymphocyte ratio) and biochemical parameters (BUN, creatinine and total and direct bilirubin) were in normal limits. Urinalysis showed that, in all of cases, specific gravity was in normal range (1.015-1.035) and all urine samples contained normal number of erythrocytes, leukocytes, crystals and a few epithelial cells (in some cases). Microscopic examination revealed that there were no bacteria in urine samples.

Surgical treatment was carried out on all of the referred cases (36 goat kids). The goats were sedated by IV administration of Xylazine hydrochloride (Rompun ${ }^{\circledR}$, Bayer), $0.05 \mathrm{mg} \mathrm{kg}^{-1}$, then placed on dorsal recumbency and the caudal abdominal and perineal regions were prepared aseptically for urethrostomy operation. Prepuce and glans were desensitized with topical administration of 2\% Lidocaine jelly (Pasture
Institute, Iran). The urethral process and glans penis were exposed with caudal retraction of the prepuce. The narrowed urethral process was amputated with scissors and then the urine was spontaneously voided. A lubricated sterile urine catheter was placed in the urethra.

For permanent urethrostomy, local anesthesia was used by circumferential injection of $1 \%$ Lidocaine hydrochloride solution (Pasture Institute, Iran) around the diverticulum. Then a small elliptical incision $(1.5-2 \mathrm{~cm})$ was carried out on the midline skin at urine pool region. The skin and subcutaneous tissue was excised and after control of bleeding, penile urethrostomy was performed by suturing the urethral mucosa to the skin with 3-0 nylon (Teb Keyhan, Iran) or 3-0 Polyglycolic Acid (PGA, Teb Keyhan, Iran) sutures in a simple interrupted pattern Fig. 2. Immediately after operation the kids urinated incontinently, without difficulty, after that the urethral catheter was removed.

Postoperative treatments included intramuscular injection of Penicillin-Streptomycin (20000 IU kg-1 to $20 \mathrm{mg} \mathrm{kg}^{-1}$ ) for 5 days, daily lavage of wound with normal saline and topical administration of Nitrofurazone ointment. After 2 weeks, there were no significant complications in surgical region and all kids were completely normal. Two months after operation, there is no complaining about postoperative complications from goat's owners.

\section{RESULTS AND DISCUSSION}

Hypospadias, a more extreme form of congenital urethral defect, is seen in young phenotypically male goats. In hypospadias, the urethra remains open on the ventral surface of the penis and is visible externally on the preputial midline (Smith and Sherman, 1994). In human, hypospadias is the second most common congenital abnormality after cryptorchidism (Pierik et al., 2002). With an incidence of 1:300; hypospadias is one of the most common genital anomalies in human male new borns (Djakovic et al., 2008; Leung and Robson, 2007), but occurs rarely in domestic animals (Bleul et al., 2007).

Surgical reconstruction is the only possible therapeutic option for hypospadias (Leung and Robson, 2007). In human medicine, the goal of hypospadias surgery is to create a straight penis that is adequate for sexual intercourse, to reposition the urethral meatus and establish good cosmetic results that include a conically shaped glans. Base on anatomical position of urethral orifice and kind of abnormalities, many procedures have been designed for the repair of hypospadias and no single 
procedure is suitable for all cases (Djakovic et al., 2008; Leung and Robson, 2007).

Alam et al. (2005) reported surgical treatment of 3 hypospadiac calves. In his study, urethrostomy associated with castration was carried out for treatment of the patients. He suggested that the calves urinated normally postoperatively (Alam et al., 2005).

The urethral process is commonly amputated therapeutically and sometimes prophylactically in small ruminant breeding male (Smith and Sherman, 1994).

Hypospadias is thought to be inherited in sheep and dogs but this has not been confirmed because there have not been sufficient cases to study (Dennis, 1974; Hayes and Wilson, 1986). Radostits et al. (2007) suggested that no genetic influence was suspected and the cause was unidentified in animals. In cattle hypospadias is attributable to a genetic defect in only $25 \%$ of affected animals (Bleul et al., 2007). Similarly, only $31 \%$ of men with hypospadias have a genetic or chromosomal defect (Boehmer et al., 2001). Because a heritable component for hypospadias cannot be ruled out, affected animals should be castrated (Bleul et al., 2007). It is recommended that do not use animals with hypospadis for breeding (Fossum, 2002).

In our previous study, Sakhaee and Azari (2009) suggested that grazing in pistachio orchards may play an important role in this abnormality, because the most of the hypospadic goats were fed by pistachio leaves and outer shells.

Early complications of hypospadias repair include bleeding, hematoma, wound infection, wound dehiscence and urinary tract infection (Stokowski, 2004; Synder et al., 2005). Some late complications include urethrocutaneous fistula, urethral stricture, balanitis and urethrocele (Nuininga et al., 2005; Soomro and Neal, 1998). Alam et al. (2005) stated that postoperative complications in hypospadias calves included partial wound dehiscence in one calf (of 3 calves), resulting in second intention healing of the incision (Alam et al., 2005).

In our study, there was no major complication such as significant wound infection, complete dehiscence of sutures, obstruction in the artificial opening and dysuria after urethrostomy operation in operated kids. In 2 cases partial suture dehiscence were observed that has been allowed to repair in second intention wound healing.

In Canine scrotal or prescrotal urethrostomy techniques, Bjorling (2003) suggested that the urethra is sutured to the skin using monofilament nonabsorable suture material, whereas Fossum (2002) recommended absorbable suture materials. Monofilament nonabsorbable suture material is used to appose the edge of the urethral mucosa to adjacent skin adge for urethrostomy in goat (Tibary and Van Metre, 2004). Alam et al. (2005) was used nylon for suturing of urethra to skin in hypospadia calves. Suture removal is performed two weeks after surgery when the nonabsorbable suture material is used (Tibary and Van Metre, 2004).

In our study, Nylon sutures were removed 1214 days after operation and Polyglycolic acid sutures were left in the surgical site. The kind of suture materials had no significant effects on occurrence of postoperative complications.

\section{CONCLUSION}

In present study, the aim of urethrostomy operation in goat kids was relief of dysuria, stranguria and other complications following hypospadias and also in order to economic purpose for animal owners. Since the operated animals were in high risk for involvement of ascending infections in urogenital tract, it was recommended to the owners, the animals sacrificed after fattening for feeding purpose.

\section{ACKNOWLEDGMENT}

This research was financially supported by research council of Shahid Bahonar University of Kerman.

\section{REFERENCES}

Alam, M.R., S.H. Shin, H.B. Lee, I.H. Choi and N.S. Kim, 2005. Hypospadias in three calves: A case report. Vet. Med. Czech., 11: 506-509. http://old.vri.cz/docs/vetmed/50-11-506.pdf

Bjorling, D.E., 2003. The Urethra. In: Text Book of Small Animal Surgery, Slatter, D. (Eds.), 3rd Edn., WB Sunders Company, Philadelphia, USA., ISBN: 0-7216-8607-9, pp: 1640-1643.

Bleul, U., F. Theiss, M. Rutten and W. Kahn, 2007. Clinical, cytogenetic and hormonal findings in a stallion with hypospadias-A case report. Vet. J., 173: 679-682. DOI: $10.1016 / j . t v j 1.2006 .03 .005$

Boehmer, A.L., R.J.M. Nijman, B.A.S. Lammers, S.J.F. de Coninck and J.O. Van Hemel et al., 2001. Etiological studies of severe of familial hypospadia. J. Urol., 165: 1246-1254. PMID: 11257695

Boothe, H.W., 2003. Penis, Prepuce and Scrotum. In: Text Book of Small Animal Surgery, Slatter, D. (Eds.), 3rd Edn., WB Sunders Company, Philadelphia, USA., ISBN: 0-7216-8607-9, pp: 1535. 
Dennis, S.M., 1974. A survey of congenital defects of sheep. Vet. Rec., 95: 488-490. PMID: 4155810

Djakovic, N., J. Nyarangi-Dix, A. Ozturk and M. Hohenfellner, 2008. Hypospadias. Adv. Urol., 2008: 1-7. DOI: $10.1155 / 2008 / 650135$

Fossum, T.W., 2002. Surgery of the Male Reproductive Tract. In: Small Animal Surgery, Fossum, T.W., C.S. Hedlund, D.A. Hulse, A.L. Johnson and H.B. Seim et al. (Eds.), 2nd Edn., Mosby, Inc., Elsevier Science Company, USA., ISBN: 0-32301238-8, pp: 662-663.

Hayes, H.M. and G.P. Wilson, 1986. Hospital incidence of hypospadias in dogs in North America. Vet. Rec., 118: 605-607. PMID: 3487876

Leung, A.K.C. and W.L.M. Robson, 2007. Hypospadias: An update. Asian J. Androl., 9: 16-22. DOI: 10.1111/j.1745-7262.2007.00243.x

Nuininga, J.E., R.P.E. de Gier, R. Vetschuren and W.F. Feitz, 2005. Long-term outcome of different types of 1-stage hypospadias repairs. J. Urol., 174: 1544-1548. PMID: 16148649

Pierik, F.H., A. Burdorf, J.M.R. Nijman, R.E. Juttmann and S.M.P.F. de Munick Keizer-Scharama et al., 2002. A high hypospadis rate in the Netherlands. Hum. Reprod., 17: 1112-1115. PMID: 11925415

Radostits, O.M., C.C. Gay, K.W. Hinchcliff and P.D. Constable, 2007. Veterinary Medicine. 10th Edn., Saunders Co., London, ISBN: 0-7020-2777-4, pp: 573.
Sakhaee, E. and O. Azari, 2009. Hypospadias in goats. Iranian J. Vet. Res. Shiraz Univ., 10: 298-301. http://www.sid.ir/en/VEWSSID/J_pdf/1023200928 16.pdf

Silver, R.I., 2000. What is the etiology of hypospadias, a review of recent research. Delaware Med. J., 72: 343-347. PMID: 10984977

Smith, M.C. and D.M. Sherman, 1994. Goat Medicine. 1st Edn., Lea and Febiger, Williams and Wilkins, USA., ISBN: 0-8121-1478-7, pp: 388-389, 393.

Soomro, N.A. and D.E. Neal, 1998. Treatment of hypospadias: An update of current practice. Hospital Med., 59: 553-559. PMID: 9798545

Stokowski, L.A., 2004. Hypospadias in neonate. Adv. Neonatal Care, 4: 463-472. PMID: 15368213

Synder, C.L., A. Evangelidis, G. Hasen, S.D. Peter and D.J. Ostlie et al., 2005. Management of complications after hypospadias repair. Urology, 65: 782-785. PMID: 15833528

Tibary, A. and D. Van Metre, 2004. Surgery of the Sheep and Goat Reproductive System and Urinary Tract. In: Farm Animal Surgery, Fubini, S.L. and N.G. Ducharme (Eds.). Sunders, Elsevier, USA., ISBN: 0-7216-9062-9, pp: 539-540. 